Massariol, D.N. Horizonte iusnaturalista de impronta cristiano-humanista en la «justicia social» del programa estético oficial peronista (1946-1955) . Derecho y Ciencias Sociales. Noviembre 2020 - Abril 2021. No 24 .Pgs 79 -99 ISSN 1852-2971. Instituto de Cultura Jurídica y Maestría en Sociología Jurídica. Facultad de Ciencias Jurídicas y Sociales. Universidad Nacional de La Plata. Argentina.

\title{
Horizonte iusnaturalista de impronta cristiano-humanista en la «justicia social» del programa estético oficial peronista (1946-1955)
}

\author{
Iusnaturalist Horizon and Christian-humanist Imprint on "Social Justice" in the Peronist \\ Official Aesthetic Program (1946-1952)
}

\section{Resumen}

Diego N. Massariol

En el presente artículo se exploran los fundamentos del sistema jurídico peronista a partir de un corpus de textos visuales (afiches políticos, ilustraciones hemerográficas y libros oficiales de propaganda gráfica) producidos, financiados y difundidos por el Estado argentino entre 1946 y 1955. Se observa en ellos una insistente estilización de la «justicia» alineada a contenidos nucleares ampliamente convencionalizados de la tradición católica pero vinculada siempre a figuras humanas y signos de connotación nacionalista que terminan reorientando la interpretación original hacia campos tópicos recurrentemente cercanos a «divina justicia social». A partir de esta manipulación sígnica se buscará sostener que la «justicia social» peronista producida en su programa estético oficial se fundamentaría en un contenido suprapositivo católico de expresión cristiano-humanista, progresivamente secularizado hacia las bases de un nacionalismo social. Para tal fin, se investigarán los principios ontológicos generales del Derecho justicialista, su posicionamiento doctrinario en el escenario normativo contemporáneo y el resultante ordenamiento legal positivo propuesto. Se espera con ello contribuir a los estudios del fenómeno peronista desde una lectura iusfilosófica de su obra gráfica oficial y confirmar la condición interactivamente convergente de su proyecto políticocultural.

Palabras Clave: Filosofía del derecho, Ontología jurídica, Nacionalismo, Catolicismo, Semiótica.

\section{Abstract}

This article explores the basis of the Peronist legal system from a corpus of visual texts (political posters, hemerographic illustrations and official graphic propaganda books) produced, financed and disseminated by the Argentine State between 1946 and 1955. It is observed an insistent stylization of «social justice» aligned with widely conventionalized nuclear contents of the Catholic tradition but linked to human figures and nationalist-oriented sign fields that redirect the original interpretation towards topical fields recurrently close to "divine social justice". Therefore, based on this signical manipulation, it will be sought to maintain that the Peronist "social justice" produced in its official aesthetic program would be based on a suprapositive Catholic content of Christian-humanist expression, progressively secularized towards the foundations of a social nationalism. It is investigated the general ontological principles of Peronist law, its doctrinal positioning in the contemporary normative scenario and the resulting proposed positive legal order. It is expected to contribute to the studies of the Peronist phenomenon with an iusphilosophical lecture of its official graphic work and to confirm the interactively convergent condition of the justicialist political-cultural project.

Key words: Philosophy of Law, Legal Ontology, Nationalism, Catholicism, Semiotics.

\footnotetext{
- Instituto de Teorìa e Historia del Arte "Julio Payró", Facultad de Filosofía y Letras, Universidad de Buenos Aires..dmassariol.uba@gmail.com
} 
Massariol, D.N. Horizonte iusnaturalista de impronta cristiano-humanista en la «justicia social» del programa estético oficial peronista (1946-1955) . Derecho y Ciencias Sociales. Noviembre 2020 - Abril 2021. № 24 .Pgs 79 -99 ISSN 1852-2971. Instituto de Cultura Jurídica y Maestría en Sociología Jurídica. Facultad de Ciencias Jurídicas y Sociales. Universidad Nacional de La Plata. Argentina.

\section{Horizonte iusnaturalista de impronta cristiano-humanista en la «justicia social» del programa estético oficial peronista (1946-1955) ${ }^{1}$}

Diego N. Massariol

«El mundo del futuro será solamente de los que posean las virtudes que Dios inspiró como norte de la vida de los hombres» (Perón 1944).

\section{Introducción}

En el presente estudio se exploran los fundamentos del orden jurídico peronista a partir de un corpus de textos visuales (afiches políticos, ilustraciones hemerográficas y libros oficiales de propaganda gráfica) producidos, financiados y difundidos por el Estado argentino entre 1946 y 1955. Esta indagación se inscribe en el marco de un proyecto de doctorado interesado en estudiar el alcance del programa estético oficial configurado durante la consolidación institucional del Justicialismo. Adscriptos a esa línea de estudio, aquí se investigarán los principios ontológicos generales del Derecho peronista, su posicionamiento doctrinario en la tradición y el resultante ordenamiento legal positivo con el propósito general de ampliar las interpretaciones sobre su proyecto socio-político-cultural.

Esta problemática se incluye en un área epistemológica - escasamente revisada por la bibliografía académica - que ha tomado como objeto de análisis a la política jurídica de los primeros dos gobiernos de Perón (Caimari, 2004; Cholvis, 2015; Palacio, 2018), especialmente en su dialogicidad con el escenario normativo mundial contemporáneo (Jaramillo, 2015, 2017; Pestanha, 2015; Horowitz, 1992) y con la tradición doctrinaria nacional (Soler 1966). Aunque con algunas variantes, esta línea de estudio ha exhibido abiertamente categorías analíticas inscriptas al interior de una filosofía jurídica suscripta a una condición dirigida, no-neutral de la fundamentación y aplicación del Derecho en su aspecto naturalmente político ( $v$. Kirchheimer, 2001; Höffe, 1979). Como consecuencia, ha desembocado en investigaciones sobre el accionar de los tribunales de justicia durante nuestro mismo período (Bergalli, 1984; Santiago, 2001; Tanzi, 1995), poniendo especial interés en las relaciones políticas existentes entre el poder ejecutivo y el judicial (Abásolo, 2002; Mercilese, 2010). En base a ello, aquí se continuará con esta misma manera de pensar el Derecho, por

\footnotetext{
${ }^{1}$ Basado en el proyecto para optar por el título de Doctor en Historia y Teoría de las Artes (FFyL-UBA): «El programa estético oficial peronista y la construcción de su "hegemonía” (1946-1952)». Dir: Dr. Hugo R. Mancuso; Co-Dir: Dra. Alejandra Niño Amieva; radicado en el Instituto de Teoría e Historia del Arte "Julio Payró" (ITHA-FFyL) y financiado por el Consejo Nacional de Investigaciones Científicas y Técnicas (CONICET).
} 
Massariol, D.N. Horizonte iusnaturalista de impronta cristiano-humanista en la «justicia social» del programa estético oficial peronista (1946-1955) . Derecho y Ciencias Sociales. Noviembre 2020 - Abril 2021. № 24 .Pgs 79 -99 ISSN 1852-2971. Instituto de Cultura Jurídica y Maestría en Sociología Jurídica. Facultad de Ciencias Jurídicas y Sociales. Universidad Nacional de La Plata. Argentina.

cuanto que el orden jurídico-normativo se sobreentenderá en adelante como sustento y andamiaje necesarios de la transformación socio-cultural buscada por el gobierno.

Por su parte, abundan lecturas eruditas sobre el catolicismo argentino (Ghio, 2007; Mallimaci, 1988; Zanatta, 1996; Zanca, 2006, 2013 entre otros) y, en especial, sobre el diálogo catolicismo-nacionalismo de las décadas de 1930 y 1940 (Buchrucker, 1987; Devoto, 2002; Mallimaci, 2011; Zuleta Álvarez, 1975). Esta amplia tradición de estudios ha definido casi con unanimidad a la Iglesia Católica argentina como un protagonista central del derrotero político de la primera mitad del siglo. Desde allí se ha insistido en explicitar la existencia de un proyecto de confesionalización de la Nación y de refundación del Estado argentino sobre la base de un principio distinto al liberal para mostrar los motivos de una vinculación orgánica con el Ejército y con los nacionalismos contemporáneos. Esta alianza es la que le permitirá a la historiografía fundamentar el basamento ideológico del Justicialismo en el catolicismo de finales de los años 30 (Bianchi, 1988; Bosca, 1997; Caimari ,1994; Lida, 2005; Zanatta, 1999), tal el que será revisitado aquí para indagar en los aspectos iusfilosóficos de su doctrina.

En el marco de este esquemático estado general de conocimientos sobre el tema-problema, la presente investigación busca contribuir con los estudios jurídico-culturales del fenómeno peronista desde el análisis de su obra gráfica oficial. Se inscribe epistemológicamente en los lineamientos de una semiótica general de la cultura (Eco, 1975, 1979; Rossi-Landi, 1972, 1985) — como teoría de lo social y praxis sígnica (Mancuso, 2005, 2010) — para aplicar la metodología propuesta por la semiótica textual (Eco 1975, 1979a, 1979b, 1984, 1997; Mancuso \& Niño Amieva 2011, 2015, 2016) sobre un corpus cualitativamente significativo de textos visuales oficiales y analizar su manipulación sígnica al interior de un diálogo con la tradición. Se advierte en ellos que la estilización de la «justicia» se presenta comúnmente alineada a contenidos nucleares ampliamente convencionalizados de la enciclopedia católica pero vinculada siempre a la estilización de signos de connotación nacionalista que terminan reorientando la interpretación hacia campos tópicos recurrentemente cercanos a «divina justicia social». A partir de esta corrección semiótica, en lo siguiente se sostendrá que la naturaleza del orden jurídico propuesto por el Justicialismo en su programa estético oficial se apoyaría en un contenido suprapositivo católico de expresión cristiano-humanista pero progresivamente secularizado hacia las bases de un nacionalismo popular. Para tal fin, se expondrá y se actualizará interpretativamente el corpus visual detectando sus modos de producción sígnica para analizar y discutir sus topics; luego se estudia el viraje filosófico del catolicismo argentino de la década de 1930 (influenciado por la nueva cristiandad y el 
Massariol, D.N. Horizonte iusnaturalista de impronta cristiano-humanista en la «justicia social» del programa estético oficial peronista (1946-1955) . Derecho y Ciencias Sociales. Noviembre 2020 - Abril 2021. № 24 .Pgs 79 -99 ISSN 1852-2971. Instituto de Cultura Jurídica y Maestría en Sociología Jurídica. Facultad de Ciencias Jurídicas y Sociales. Universidad Nacional de La Plata. Argentina.

humanismo integral de Jacques Maritain como respuesta a la cuestión social) con el fin de definir el corpus ideológico que fundamenta al Justicialismo; a continuación se explica el programa legislativo propuesto por los primeros gobiernos de Perón para explicitar su inscripción doctrinaria en la renovación jurídica antiliberal y antipositivista del derecho social; finalmente se discuten los hallazgos y se ensayan conclusiones provisionales. Con esto se espera actualizar los estudios jurídicos sobre el peronismo y confirmar la condición interactivamente convergente de su proyecto socio-político-cultural.

\section{Descripción del corpus y análisis teórico-metodológico}

En lo siguiente se reconstruye un corpus de textos visuales producidos por el Estado argentino en el contexto de una progresiva centralización de la comunicación pública. En este sentido, el corpus aquí definido repone imágenes que originalmente aparecieron en libros oficiales de propaganda, revistas culturales y afiches políticos de amplia circulación en la cultura popular de la segunda mitad de la década de 1940 y principios de 1950. En su mayoría, se ha detectado que el diseño de estas ilustraciones corresponde a un trabajo conjunto realizado en el taller gráfico de sus respectivas editoriales. Es por ello que, si bien el contenido ideológico era provisto en todos los casos por la oficina de Control de Estado, la resolución visual de sus configuraciones significantes presenta una amplia variedad estilística, razón por la cual el criterio de selección aplicado sobre los textos que integran el corpus responde al valor que poseen para expresar la intención oficial de problematizar y discutir la naturaleza del sistema de justicia nacional. Asimismo, entre todo el material recolectado, se ha procedido a discriminar aquellos textos que explicitan mismos modos de producción sígnica al interior de un diálogo con la tradición visual de la cultura argentina y que, por ello, presentan un común universo de topics vinculados a los términos clave «justicia», «sociedad», «divinidad», «nación». De ellos, también se han privilegiado los que tuvieron mayor visibilidad, sea por el espacio en el que circularon o sea por el medio gráfico que los publicó. Atento lo expuesto, la definición final del conjunto responde a su capacidad para habilitar cualitativamente el análisis de la manipulación sígnica oficial que aquí se busca sostener y fundamentar la existencia de un programa oficial destinado a delinear las características de un esquema estético propio, cooperante en la redefinición de los significados públicos mediante la generación de nuevos contenidos molares y, en tanto tal, en la expansión de su proyecto político.

El primer texto detectado proviene de La Nación argentina justa, libre y soberana (Figura 1). En él se reproduce la estilización de una figura humana femenina que sostiene una espada 
Massariol, D.N. Horizonte iusnaturalista de impronta cristiano-humanista en la «justicia social» del programa estético oficial peronista (1946-1955) . Derecho y Ciencias Sociales. Noviembre 2020 - Abril 2021. № 24 .Pgs 79 -99 ISSN 1852-2971. Instituto de Cultura Jurídica y Maestría en Sociología Jurídica. Facultad de Ciencias Jurídicas y Sociales. Universidad Nacional de La Plata. Argentina.

de doble filo en su mano izquierda y una balanza en su derecha. La convención de sus atributos lleva a identificar a esta figura inmediatamente con la personificación de la «justicia», lo cual es reforzado por el texto desde las unidades combinatorias reproducidas en su margen inferior para formar los sintagmas «justicia»y «social». Con estas estilizaciones el texto está retomando contenidos ampliamente legitimados de la tradición visual, en una relación espécimen/tipo expresivo que no intenta modificar ni corregir, para invitar a una lectura fácilmente decodificable por la cultura popular de entonces.



Figura 1. Justicia social (1950). S/fi. En La Nación Argentina Justa Libre Soberana. Buenos Aires: Peuser S.A.
Sin embargo, la «justicia» aquí reproducida se presenta vestida con una indumentaria que, por la pesadez y por el tono ascético de su tela, pareciera tratarse de una cogulla monacal medieval, similar a la usada por los franciscanos (aunque no explícitamente). En las reproducciones más convencionales, la personificación de la «justicia» aparece vestida con el peplo griego drapeado al estilo clásico; pero la presencia de este signo vinculado a los hábitos de una orden regular $-\mathrm{y}$ que por ello se presenta refiriendo por ratio facilis a la liturgia clericalorienta interpretativamente la lectura de esta «justicia», hipercodificándola hacia una exégesis indefectiblemente cristiana. Esto parece confirmarse con la producción de un espectro de color insaturado y de valor alto que la rodea, el cual se reconoce dentro de la tradición como una «mandorla»y que permite inferir con ello la presencia de un resplandor de luz de naturaleza divina/divinizada (Cfr. Figura 4).

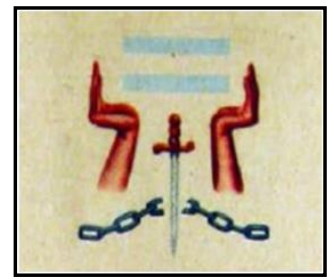

Figura 2. Emblema de justicia social. (1950). S/fi. En La Nación Argentina Justa Libre y Soberana. $3^{\circ}$ ed. Buenos
La espada que porta en su mano izquierda, si bien es un elemento ya presente en el motivo iconográfico convencionalizado de la «justicia» civil griega, también podría estar receptando aquí un significado confesional que permita leer a todo el motivo en clave católica. Esta interpretación se respalda en abundantes referencias bíblicas y de textos litúrgicos, ampliamente circulantes en ese contexto. Particularmente, la enciclopedia convocada podría referirse tanto a la «espada de dos filos» con la cual Pablo exhorta a combatir «contra las asechanzas del diablo» (Ef 6:13), como también a relatos del Antiguo y del Nuevo Testamento en donde el motivo de la «espada» se presenta insistentemente codificado como «espada de Dios»/«espada del Espíritu»/«arma de luz»/«fuerza espiritual» con la que Dios (o sus enviados) imparten paz y justicia en el Mundo. (Cfr. S1 149:5-8; Ap 1:16, entre otros). Por 
Massariol, D.N. Horizonte iusnaturalista de impronta cristiano-humanista en la «justicia social» del programa estético oficial peronista (1946-1955) . Derecho y Ciencias Sociales. Noviembre 2020 - Abril 2021. № 24 .Pgs 79 -99 ISSN 1852-2971. Instituto de Cultura Jurídica y Maestría en Sociología Jurídica. Facultad de Ciencias Jurídicas y Sociales. Universidad Nacional de La Plata. Argentina.

todo ello, este motivo parece configurarse como un cuadro fuertemente vinculable a numerosos co-textos bíblicos que, en una semiosis de fuerte predominio clerical como la de la década de 1940 argentina, abren ineludiblemente lecturas religiosas.

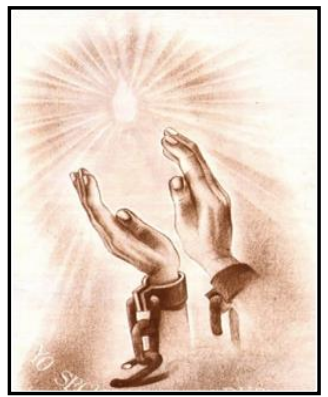

Figura 3. $S / t$ (1953). Cary (Il.). En Mundo Peronista. II, 38, $19.1^{\circ}$ de Febrero.

Al respecto, en un emblema de página que aparece al comienzo del mismo libro (Figura 2), la estilización de este motivo se dispone interponiéndose entre las cadenas para romperlas. El juego sígnico lleva a reconocer, a medio camino entre la ratio facilis y la ratio dificillis, una idea de «libertad» que pasa a estar asociada ahora a la «espada de la justicia». Este mismo postulado de «justicia manumisora» está también presente en una ilustración co-textual de la revista Mundo Peronista (Figura 3), aunque aquí su connotación sacralizada pareciera ser más explícita al reproducir el mismo motivo de «cadenas rotas» pero junto a una «llama de fuego brillante». De continuar con la misma exegesis católica, sería aceptable entonces que aquella liberación fuera interpretada como una intervención divina y, por ello, que el topic de ambas — con distinto grado de literalidad pero con igual orientación — naturalmente derive hacia «divina justicia redentora». Ahora bien, tal como ocurre en el emblema (y en una gran cantidad de otros textos del mismo tipo), en la Figura 1 se reproduce la estilización legiblemente simple de la «bandera nacional argentina». Esta incorporación provoca la aparición de una vectorialidad de profundidad (delante/detrás) y de una vectorialidad direccional (vertical/horizontal) que conduce a percibir una superposición entre ambos signos y, por ello, a una necesaria implicación intersígnica. Atento a ello, el texto abre la lectura a dos posibles nuevas interpretaciones (no excluyentes): (1) la alusión explícita a la forma de una cruz, lo cual presenta un claro contenido católico; (2) la reproducción de un eje de coordenadas cartesiano que permite inferir la postulación de una coincidencia temporal entre la «divina justicia» y la «nación».

Esta segunda lectura permite advertir que, aunque todos estos textos estén convocando redundantemente enciclopedias confesionales, la propuesta de intervenir a la «justicia»con cuadros nacionalistas busca reformular la interpretación final hacia tópicos del tipo: «el advenimiento de la divina justicia en la Nación argentina». Asimismo, si a este recorrido inferencial se le incluye la cartela superior de unidades combinatorias que conforman la cita de autoridad del discurso de Perón, ${ }^{2}$ podría además detectarse un contenido político en este

\footnotetext{
${ }^{2}$ La cartela superior dice: «La agitación de las masas es un efecto de la injusticia social. El remedio no ha de estar en engañarlas ni en someterlas a la fuerza, sino en hacer justicia. Perón.».
} 
Massariol, D.N. Horizonte iusnaturalista de impronta cristiano-humanista en la «justicia social» del programa estético oficial peronista (1946-1955) . Derecho y Ciencias Sociales. Noviembre 2020 - Abril 2021. № 24 .Pgs 79 -99 ISSN 1852-2971. Instituto de Cultura Jurídica y Maestría en Sociología Jurídica. Facultad de Ciencias Jurídicas y Sociales. Universidad Nacional de La Plata. Argentina.

proceso de secularización. Por todo ello, una primera actualización interpretativa de aquel texto devenida de sus modos de producción sígnica posibilita la postulación de un topic final del tipo: «el advenimiento de la divina justicia en la Nación argentina por el Justicialismo».

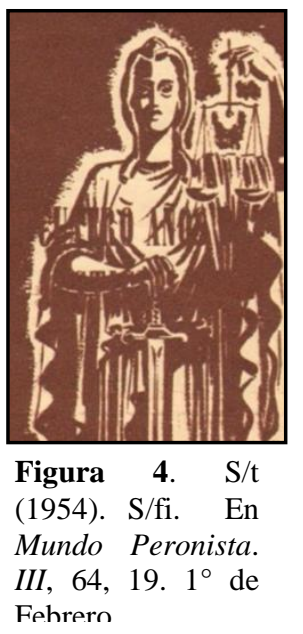

En otro texto del mismo compendio (Figura 5) se vuelve a reproducir la estilización de una figura femenina como motivo central, cuya interpretación está claramente indicada por las unidades combinatorias que producen los sintagmas «ayuda» $\mathrm{y}$ «social». En este caso, la personificación de la «justicia» presenta una vestimenta similar a un quitón clásico con gorro frigio, los cuales son atributos y rasgos distintivos que permitirían reconocerla como la representación profana de la «república». Esta corrección semántica de la «justicia» respecto a la Figura 1, mediante la cual el motivo femenino central está presentado con atributos laicos, no es inocente en cuanto a que, al producir la estilización de cuadros nacionalistas — tal la banda que enmarca a la figura- y, con ello, convocar otras competencias interpretativas, el texto pareciera a priori estar postulando una lectura plenamente secular.

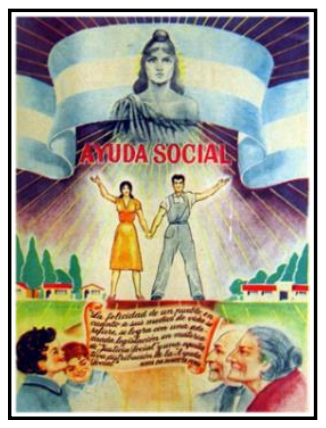

Figura 5. Ayuda Social. (1950). S/fi. En $L a$ Nación Argentina Justa Libre y Soberana. $3^{\circ}$ ed. Buenos Aires: Peuser.
Sin embargo, la enciclopedia religiosa aparece convocada por dos modos de producción sígnica bien definidos y complementarios. En principio, (1) la disposición de esta estilización en un plano alto respecto al resto de las figuras humanas estilizadas permite advertir una vectorización espacial (arriba/abajo) que refuerza la posibilidad de leer en el texto una oposición entre dos mundos (material/espiritual-humano/celestial). De esta manera, el texto aumenta intuitivamente el contenido sacro de la figura femenina y, por ello, su lectura religiosa. Pero también, (2) la estilización de la «justicia/república» aparece asociada sígnicamente a vectores estilizados en tonos amarillos que parecen irradiarse sobre el espacio textual. Al respecto de este modo de producción, interesa destacar especialmente un afiche de 1948 (Figura 6) en el cual aparece estilizada la figura simbólica de la «justicia». Allí la «balanza»y el «gorro frigio» en claro proceso metonímico reactualizan la misma interpretación laica del Derecho, en adición a la «escarapela» que le otorga un sesgo nacionalista. Pero al presentarse todo ello asociado a la estilización de un «rompimiento de gloria», la lectura final queda imposibilitada de eludir el 
Massariol, D.N. Horizonte iusnaturalista de impronta cristiano-humanista en la «justicia social» del programa estético oficial peronista (1946-1955) . Derecho y Ciencias Sociales. Noviembre 2020 - Abril 2021. № 24 .Pgs 79 -99 ISSN 1852-2971. Instituto de Cultura Jurídica y Maestría en Sociología Jurídica. Facultad de Ciencias Jurídicas y Sociales. Universidad Nacional de La Plata. Argentina.

contenido religioso que el texto busca hacer explícito, clausurándose hacia una interpretación asociada a la gracia de la justicia.

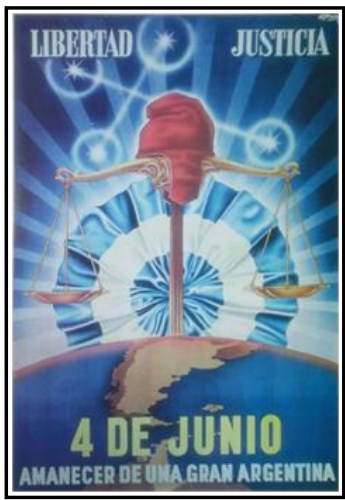

Figura 6. 4 de Junio. (1948). Alfonsín (dis.). Buenos Aires: SIPA.

Por su parte, en todos estos casos, la estratégica operación sígnica mixta de estilización/vectorización de la «luz» activa un proceso inferencial ligado a la idea de un «descenso desde el plano celestial al terrenal»; procedimiento sígnico que, de ser leído desde una enciclopedia religiosa, permite inferir la idea de un «advenimiento sagrado» o (más específicamente desde una lectura católica) al «advenimiento del Espíritu Santo». ${ }^{3}$ Esta misma interpretación de la «justicia» ya había aparecido en la Figura 3, aunque allí su estilización como «lengua de fuego» pareciera estar reproduciendo otra de las formas iconográficas de la tradición visual católica basada en el relato de Pentecostés. ${ }^{4}$ De esta manera, todos estos textos receptan signos de las Escrituras bíblicas ya codificados y ampliamente convencionalizados en la cultura pero corregidos semióticamente hacia un interpretante civil, laico, no-confesional y de orientación nacionalista. De allí también se desprende que hasta aquí, con mayor o menor grado de negociación en la lectura pero unánimemente en todos los casos analizados, sus modos de producción sígnica habiliten la postulación de ideas asociadas a una «divina justicia» que se ha secularizado.

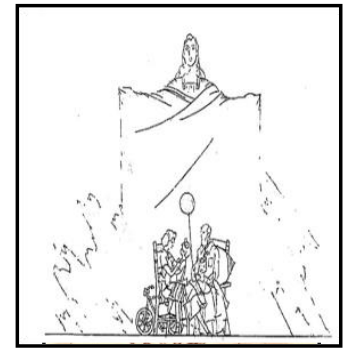

Figura 7. S/t. (1951). S/fi. En Argentina en Marcha, Buenos Aires: SIPA.

Figura 8. S/t (1952). S/fi. En Mundo Peronista. II, 27, 47. 15 de Agosto.
Ahora bien, a diferencia de los demás textos del corpus, en la Figura 5 también se produce la estilización de figuras humanas. Esta inclusión respecto a las otras no es menor en tanto que de esta manera pareciera estarse reproduciendo una articulación semiótica entre los signos y, por ello, animando una actualización de la «justicia» no sólo como entidad divina sino también como proyecto social. Si se atiende a una ilustración aparecida en Argentina en marcha de 1951 (Figura 7), la estilización hiperbólica de la «justicia» respecto a las demás vuelve a denotar su condición

\footnotetext{
${ }^{3}$ Sobre este tópico, en la Figura 5 se traduce (por poco, literalmente) el pasaje bíblico neotestamentario del primer sermón de Pedro a los habitantes de Jerusalén en el cual les narra la profecía de Joel para poder explicar el Veni Sancte Spirtus:«Sucederá que en los últimos días - dice Dios— derramaré mi Espíritu sobre todo el género humano. Vuestros hijos e hijas profetizarán, tendrán visiones los jóvenes y sueños los ancianos. En esos días derramaré mi Espíritu aun sobre mis siervos y mis siervas y profetizarán» (He 2:17-18).

${ }^{4}$ «Y de repente vino del cielo un estruendo como de un viento recio que soplaba, el cual llenó toda la casa donde estaban sentados; y se les aparecieron lenguas repartidas, como de fuego, asentándose sobre cada uno de ellos Todos fueron llenos del Espíritu Santo y comenzaron a hablar en otras lenguas, según el Espíritu les daba habilidad para expresarse» (He 2:2-3).
} 
Massariol, D.N. Horizonte iusnaturalista de impronta cristiano-humanista en la «justicia social» del programa estético oficial peronista (1946-1955) . Derecho y Ciencias Sociales. Noviembre 2020 - Abril 2021. № 24 .Pgs 79 -99 ISSN 1852-2971. Instituto de Cultura Jurídica y Maestría en Sociología Jurídica. Facultad de Ciencias Jurídicas y Sociales. Universidad Nacional de La Plata. Argentina.

suprahumana. Sin embargo, esta producción sígnica difiere fuertemente de los modelos convencionalizados en tanto que su disposición a abrir su manto con sus manos para contener y resguardar a las demás figuras del texto, recepta contenidos nucleares ampliamente convencionalizados de la enciclopedia católica que vuelven a habilitar una clara lectura sagrada del Derecho.

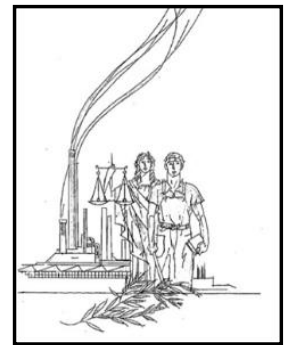

Figura 9. S/t. (1951) S/fi. En Argentina en Marcha, Buenos Aires: SIPA.
Más específicamente, la imagen pareciera reponer el gesto protector, propio de la tradición iconográfica mariana en su advocación de la Virgen de la Misericordia. De allí que la reproducción de las figuras en el espacio inferior del texto produzca una dinámica intersígnica diferente al resto de los textos visuales antes descriptos, mediante la cual se logra inferir la postulación de una función civil de la «justicia» y se puede arriesgar, aunque en una primera aproximación, un topic del estilo «la protección/el amparo

social de la divina justicia».

Esta connotación de andamiaje protector social aparece también en otra ilustración de Argentina en marcha (Figura 9) en la cual la estilización de la «justicia» produce en el texto una vectorización de profundidad (delante/detrás) en relación a la figura humana y por lo cual parece estar escoltándola. Sin embargo, la particularidad es que aquịi se ha anulado la fuerte vectorización espacial (arriba/abajo) que se reproducía en los anteriores.

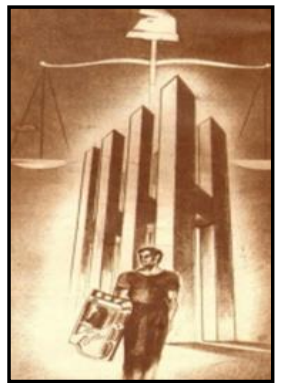

Figura $10 \mathrm{~S} / \mathrm{t}$ (1952).

S/fi. En Mundo Peronista. II, 30, 12. 1 de Octuhre

Con este cambio, ambos motivos parecen estar equiparados semióticamente e identificados mutuamente, conforme a una única definición. En este mismo sentido, la Figura 9 mantiene el recurso de ubicar a la «justicia» en un plano superior del texto para postular nuevamente una condición supraterrenal y reafirmar, con ello, su connotación sagrada; pero al reproducir la estilización de la «cabeza humana» en el mismo plano textual, vuelve a proponer una misma identidad semiótica para las dos. En definitiva, estas dos imágenes manejan los mismos modos de producción sígnica para connotarles por igual —amén de sus diferencias denotativas - un mismo contenido. Es decir, a partir de la inclusión de las figuras humanas, la vinculación de ambos signos por contigüidad produce en estos textos una desviación en el proceso inferencial de las anteriores por medio del cual se deriva interpretativamente la lectura hacia una mutua implicación semiótica entre los signos 
Massariol, D.N. Horizonte iusnaturalista de impronta cristiano-humanista en la «justicia social» del programa estético oficial peronista (1946-1955) . Derecho y Ciencias Sociales. Noviembre 2020 - Abril 2021. № 24 .Pgs 79 -99 ISSN 1852-2971. Instituto de Cultura Jurídica y Maestría en Sociología Jurídica. Facultad de Ciencias Jurídicas y Sociales. Universidad Nacional de La Plata. Argentina.

producidos que (en su mayoría) termina secularizando la interpretación original. Por ello, a partir de esta reconfiguración, se pueden descubrir campos tópicos cercanos a «divina justicia humana» o, mismo, «divina justicia social». En efecto, si a esta producción sígnica se le suman estilizaciones de rasgos político-partidarios (Figura 11, entre otras), cuya inclusión bien podría pensarse como un estímulo programado para generar una respuesta comportamental en su/s lector/es, las ideas expuestas conjuntamente en todos ellos terminan reorientando la lectura hacia un topic central del tipo: «advenimiento de la divina justicia social en la Nación argentina por el Justicialismo»; y un topic secundario del tipo: «divina justicia social redentora/libertadora».

Por todo lo expuesto, el corpus aquí definido evidencia apelar a un lector modelo ya confesionalizado e inscripto en la tradición textual católica pero no necesariamente erudito en materia doctrinal teologal. Esto se advierte en la insistente postulación de contenidos nucleares bíblicos receptados aquí para dotarle a la «justicia» una connotación divina pero interceptados con campos semióticos que terminan secularizando su definición y orientando la lectura hacia interpretantes nacionalistas. ${ }^{5}$

\section{Deriva del catolicismo nacional argentino hacia un humanismo social-cristiano}

La justicia, en efecto, no es una simple convención humana porque lo que es justo no está determinado originariamente por la ley sino por la identidad profunda del ser humano. La plena verdad sobre el hombre permite superar la visión contractual de la justicia y abrirla al horizonte de la solidaridad y del amor eternos (DSI §202-203).

La historiografía argentina ha coincidido en presentar a la Iglesia católica (en su dimensión institucional) como un protagonista central de la discusión socio-político-cultural de la década de 1930 (Ghio, 2007; Touris y Ceva, 2012; Zanatta, 1996;). Al respecto, una amplia bibliografía ha señalado que la etapa histórica abierta por la Primera Guerra Mundial habría concluido hacia 1929 con una crisis estructural del régimen democrático-constitucional, con el agotamiento del modelo agro-exportador frente al progresivo crecimiento de un modelo de sustitución de exportaciones y con un agravamiento cada vez mayor de los conflictos sociales. De esta manera, aparece de forma privilegiada un hipersigno antimoderno, antipositivista y antiracionalista que guiará la construcción de un modelo alternativo al proyecto ideológico

\footnotetext{
${ }^{5}$ De esto se desprende también que la coincidencia de mismos modos de producción sígnica, la postulación de un mismo tipo de lector modélico y, por ende, la disposición de mismos topics operen aquí como fuertes indicadores de la co-participación del corpus en la configuración de un programa estético oficial.
} 
Massariol, D.N. Horizonte iusnaturalista de impronta cristiano-humanista en la «justicia social» del programa estético oficial peronista (1946-1955) . Derecho y Ciencias Sociales. Noviembre 2020 - Abril 2021. № 24 .Pgs 79 -99 ISSN 1852-2971. Instituto de Cultura Jurídica y Maestría en Sociología Jurídica. Facultad de Ciencias Jurídicas y Sociales. Universidad Nacional de La Plata. Argentina.

liberal (hegemónico en Argentina desde la Generación del 80) y cuyo correlato principal sería el completo reordenamiento del escenario socio-cultural y la consecuente progresiva reincorporación de la influencia política en la Iglesia católica.

Paralelamente a este proceso, circulaban ideas críticas a la organización mundial basada en la división internacional del trabajo que tendieron a reorientar el nuevo rumbo postliberal hacia una propuesta de reconstruir la Argentina según los valores de una nueva identidad propiamente nacional (Barbero y Devoto 1983). Esta amplia gama de ideas convergentes al interior de lo que la literatura especializada ha definido como «nacionalismo» ha sido clasificada, (1) según la actitud asumida frente a los movimientos sociales («nacionalismo populista»/«nacionalismo restaurador»; cfr. Buchrucker, 1987); (2) por la actitud asumida frente a las formas de materialización del Estado («nacionalismo autoritario»/«nacionalismo republicano»; cfr. Zuleta Álvarez, 1975), o bien (3) por el origen y contexto de emergencia de su corpus ideológico («nacionalismo vernáculo»/«nacionalismo de exportación»; $c f r$. Jauretche $_{2}$ 1973). Sin embargo, todos ellos se han podido vincular conceptualmente por su común interpretación del liberalismo y de las ideologías de izquierda en todas sus variantes como concepciones ajenas a la Patria y enemigas de la Nación.

Como resultado de este panorama ideológico, la invocación de la Iglesia y el Ejército a la restauración de la tradición histórica y a la final expulsión del liberalismo laicisizante de la cultura argentina co-operó para que desde principios de la década de 1930 se desarrolle un catolicismo nacional dispuesto a la construcción y defensa de la «nación católica» (Zanatta, 1996). La alianza que se produce por entonces con la intención de dirigir y modelar las bases de la restauración cristiana en la identidad nacional desembocará en el nacimiento de un movimiento pastoral católico de masas custodiado por el Ejercito hacia la configuración de un proyecto clerical-castrense de cristianización general de la vida pública. Entonces, llegado el Congreso Eucarístico Internacional de 1934, el símbolo de la cruz y la espada se manifestarían públicamente unidos en un solo bloque ideológico interesado en el levantamiento de una Patria identificada con un militarismo nacional y católico.

Sin embargo, durante la segunda mitad de la década de 1930 comenzaron a circular documentos que evidencian los principios de un cambio de rumbo en el catolicismo nacional en el orden de una concepción más urgente de la cuestión social. ${ }^{6}$ Esta nueva actitud que

\footnotetext{
${ }^{6}$ V. gr. «Pastoral colectiva del Episcopado Argentino acerca de algunos problemas de la hora presente» (30 de mayo de 1936) en clara sintonía con las encíclicas «Nova impendent» [«Nuevos asuntos nos ocupan»] (2 de
} 
Massariol, D.N. Horizonte iusnaturalista de impronta cristiano-humanista en la «justicia social» del programa estético oficial peronista (1946-1955) . Derecho y Ciencias Sociales. Noviembre 2020 - Abril 2021. № 24 .Pgs 79 -99 ISSN 1852-2971. Instituto de Cultura Jurídica y Maestría en Sociología Jurídica. Facultad de Ciencias Jurídicas y Sociales. Universidad Nacional de La Plata. Argentina.

apareció en la Iglesia católica argentina ocurrió en paralelo a un proceso de reconfiguración ideológica en el Movimiento Obrero en el cual se reorienta conjuntamente desde una histórica prescindencia política hacia una común intención de participación democrática activa, derivando hacia 1936 en una politización orgánica sin partidización ((Massariol, 2018). De esta manera, la cruzada anticomunista que había distinguido al catolicismo nacional restaurador de principios de los años 30 iría virando hacia los lineamientos de un nuevo cristianismo social nacional, mayormente interesado en aportar respuestas a las injusticias producidas en la sociedad civil para sumar a los sectores populares a la vida de la Nación y, así, frenar un posible levantamiento de clase.

En medio de este cambio de prioridades, en 1936 Jacques Maritain es invitado por los C.C.C. a dictar un conjunto de clases magistrales en Buenos Aires, que serían compiladas bajo el título Para una filosofía de la persona humana y que serían la antesala de su Humanismo integral. Allí insistirá en pensar una nueva cristiandad diferente al modelo medieval en la cual lo sagrado no se imponga sobre lo humano sino que permita modelar un humanismo atento tanto a la dimensión temporal del Hombre por cuanto a su cualidad de creatura de Dios: «en este nuevo momento de la historia de la cultura cristiana, la criatura no sería desconocida ni aniquilada ante Dios; tampoco sería rehabilitada sin Dios o contra Dios; seria rehabilitada en Dios» (Maritain, 1936a:10). En este sentido, la clave de esta nueva propuesta social-cristiana pareciera sostenerse en una reivindicación de la persona humana pero que no descuida nunca su vínculo necesario con lo sagrado; i.e. «una santidad vuelta hacia lo temporal, lo secular, lo profano» (Maritain, 1936a:160). De allí se desprende entonces que el carácter religioso sea propuesto como una condición constitutiva del ser: la persona humana está esencialmente vinculada a Dios y en eso se funda su dignidad.

Sin embargo, esta atención evangélica hacia lo humano no quedaba reducida sólo a los postulados de una doctrina social. Maritain insistirá en el aspecto político de la nueva cristiandad pensando también una comunidad temporal de iguales en la que esté garantizada la libertad de acción de sus integrantes, ya que «el acto libre, además de ser el acto de la persona como tal, es la revelación de la persona a sí misma; y tal vez ese acto personal y esa revelación sean idéntica cosa» (Maritain, 1936b:100). De esta manera, Maritain propone para 1936 un proyecto general de acción socio-político-cultural cristiano que, al orientarse hacia un humanismo en el cual convergen lo espiritual, lo intelectual y lo físico, se presenta como

octubre de 1931) y «Quadragésimo anno» [«Cuadragésimo aniverasario»] (15 de mayo de 1931) de Pio XI y, por ello, con «Rerum novarum» [«De los cambios políticos»] (15 de mayo de 1891) de León XIII. 
Massariol, D.N. Horizonte iusnaturalista de impronta cristiano-humanista en la «justicia social» del programa estético oficial peronista (1946-1955) . Derecho y Ciencias Sociales. Noviembre 2020 - Abril 2021. № 24 .Pgs 79 -99 ISSN 1852-2971. Instituto de Cultura Jurídica y Maestría en Sociología Jurídica. Facultad de Ciencias Jurídicas y Sociales. Universidad Nacional de La Plata. Argentina.

una respuesta adaptada a los nuevos desafíos de la modernidad y, por tanto, más firme ante la cuestión obrera. Es por ello que la presencia de este discurso en el catolicismo nacional argentino haya tendido a reorientar — no sin conflictos (Zanatta, 1996) — su actitud tradicionalista restauradora de principios de la década hacia una mirada concentrada en la vivencialidad temporal del Hombre e interesada en atender primariamente a las injusticias sociales que padece.

Las preocupaciones manifiestas en esta nueva orientación del catolicismo argentino no serán ajenas a la década posterior (Zanatta, 1999). Las ideas de «libertad» y «autorrealización» harán eco sobre un proyecto político-social de conciliación de clases, cuya interpretación progresista de la realidad apoyará la idea de construir una nueva cultura nacional post-liberal fundada en un nuevo orden axiológico (Bianchi, 1989). Frente a ello, la exaltación moral de la clase obrera y el ideal de restituir y respetar su dignidad darán formato a una idea iusnaturalista de «justicia», también deudora de este cristianismo integral nacional de corte social-humanista, que se manifestará siempre adecuada a los intereses de la persona humana.

\section{El programa legal peronista y su diálogo con el sistema jurídico-doctrinario} occidental contemporáneo

Durante las primeras décadas del siglo XX, el sistema jurídico occidental registró fuertes cambios y transformaciones doctrinales a nivel mundial (Zimmermann 2012). El modelo dogmático burgués basado en los derechos inalienables de propiedad y libertad — derivado de la idea rectora de un sujeto formalmente libre, igual y soberano- había inspirado hegemónicamente a los ordenamientos jurídicos liberales europeos vigentes hasta entonces, configurando las bases de sus Constituciones y sus Códigos. De esta manera se había expandido un corpus ideológico de fuerte contenido individualista que tendía a organizar formalmente el derecho civil en torno a una estricta separación entre lo público y lo privado y, por ello, a justificar la jurisdicción de las instituciones creadas para preservar tal definición. En definitiva se trataba de la naturalización a nivel mundial de un discurso jurídico interesado primariamente en sostener una idea unitaria y potestativamente excluyente del ejercicio de la propiedad que permita sostener la óptima funcionalidad del libre mercado. Pero el desarrollo de la industrialización y el consecuente debilitamiento de los mecanismos de integración civil hacia un orden social cada vez más desigual y deteriorado, pondrán en tensión estas concepciones jurídicas. Especialmente, la idea liberal de «propiedad» será discutida al interior de un nuevo escenario social en el cual se agudiza progresivamente la separación entre los 
Massariol, D.N. Horizonte iusnaturalista de impronta cristiano-humanista en la «justicia social» del programa estético oficial peronista (1946-1955) . Derecho y Ciencias Sociales. Noviembre 2020 - Abril 2021. № 24 .Pgs 79 -99 ISSN 1852-2971. Instituto de Cultura Jurídica y Maestría en Sociología Jurídica. Facultad de Ciencias Jurídicas y Sociales. Universidad Nacional de La Plata. Argentina.

poseedores de los modos de producción y los trabajadores (Cordero Quinzacara 2008). Así, lo social pasa a ser interpretado como un espacio de intervención urgente que exigirá una rápida actualización en materia política y jurídica para contener la presión de la masa obrera y frenar cualquier posible avance del materialismo histórico marxista por vías institucionales (Zimmermann 1995).

Como resultado, en las primeras décadas del siglo XX emerge transnacionalmente una nueva cultura jurídica interesada en discutir la funcionalidad de la propiedad en orden de generar condiciones efectivas de promoción social y de satisfacción de necesidades mínimas vitales. Este nuevo aspecto social de los bienes personales se fundamentará en un contenido axiológico solidarista y comunitario, contrario al concepto individualista, que tenderá a transformar principalmente las relaciones productivas y su mediación estatal. En el terreno práctico, esta reforma discutía elementos como la introducción de contratos colectivos de trabajo, la legalización de algunos partidos políticos obreristas, el reconocimiento de la personería jurídica de ciertos sindicatos, la discusión sobre la responsabilidad patronal ante los accidentes de trabajo o las condiciones mínimas de seguridad y bienestar laboral general. Pero, en rigor, lo que se estaba disputando era la forma en que el corpus legal positivo y las instituciones jurídicas debían adaptarse a los nuevos fenómenos sociales para contenerlos dentro del sistema. De allí que el orden doctrinario que comenzó a expandirse, antes que una modificación coyuntural de cada una de las disciplinas legales, más bien haya sido un proceso de «socialización general del derecho» (Ewald 1997).

Argentina fue parte activa en este contexto de reformismo social global (Palacio 2018). Esto implica que cuando el Justicialismo se institucionaliza como gobierno, ya existía una desarrollada tradición jurídica nacional de antecedentes regulatorios, legales y jurisprudenciales bien definidos en el naciente fuero laboral. ${ }^{7}$ También existían referencias, aunque en menor medida, a normativas de contratación y arrendamiento rural en función de un ideal social y colectivo ${ }^{8}$ y una mínima jurisprudencia al respecto. Sin embargo, el Justicialismo diseñó un claro programa de intervención y regulación de las relaciones laborales que no se reducía sólo a la promulgación e implementación de un proyecto

\footnotetext{
${ }^{7}$ V.gr. la ley de descanso dominical (1905); ley de accidentes de trabajo (1915); de regulación del trabajo a domicilio (1918); de seguridad industrial (1921); de modalidad de pago del salario (1923); de trabajo de niños y mujeres (1924); de jornada laboral de ocho horas (1929); de «sábado inglés» (1932); de protección de la maternidad (1934); entre otras.

${ }^{8}$ V.gr. Ley de arrendamiento rural 11.170 (B.O. 26-dic-1921), derogada luego por Ley de contrato de arrendamientos agrícolas 11.627 (B.O. 18-oct-1932). También v. gr. Ley de colonización 12.636 (B.O. 18-sept1940) abrogada luego por art. 86 de Ley de riqueza forestal 13.273 (B.O. 06-oct-1948).
} 
Massariol, D.N. Horizonte iusnaturalista de impronta cristiano-humanista en la «justicia social» del programa estético oficial peronista (1946-1955) . Derecho y Ciencias Sociales. Noviembre 2020 - Abril 2021. № 24 .Pgs 79 -99 ISSN 1852-2971. Instituto de Cultura Jurídica y Maestría en Sociología Jurídica. Facultad de Ciencias Jurídicas y Sociales. Universidad Nacional de La Plata. Argentina.

normativo sino que, por sobre todo, se orientaba a la construcción de un nuevo ordenamiento jurídico general, fuertemente subsidiario del clima internacional de renovación social del derecho. En este sentido, la diferenciación respecto a los años previos se basará en el desarrollo de un marco legal para la mediación institucional en conflictos laborales que cristalizará en una fuerte jerarquización, redimensionamiento y centralización estatal en la materia.

Este proceso comenzó a operar con la conformación de la Secretaría de Trabajo y Previsión en 1943, sobre la base del antiguo Departamento Nacional de Trabajo. El nuevo espacio absorbía los departamentos y las oficinas regionales y provinciales de trabajo y se erigía como la única dependencia del Estado Nacional destinada al control, regulación y gestión de las relaciones de trabajo a partir de un sistema legal de conciliación y arbitraje entre las partes. A partir de ello se promulgó una batería de decretos, estatutos y convenios colectivos —entre ellos, el Estatuto del peón - tendientes a armonizar las relaciones laborales de los distintos gremios y restablecer y preservar el equilibrio social (Campione 2007). La progresiva jerarquización del organismo concluirá en 1949 cuando su gestión sea transferida a la esfera del recién creado Ministerio de Trabajo y Previsión. De esta forma, la transformación cualitativa operada sobre estas dependencias estatales durante los primeros gobiernos de Perón advierte la existencia de un fuerte proceso de jerarquización y centralización del fuero laboral inscripto en la avanzada global del derecho social, con el objetivo de configurar las bases de un nuevo ordenamiento jurídico fundado en el ideal de una convivencia civil armónica.

Sin embargo, el programa legislativo justicialista tomará su más alto rango jurídico en 1949 con la reforma de la Constitución Nacional. En su resolución definitiva, la nueva Ley mantenía la estructura orgánica de la anterior, aunque incorporaba derechos sociales $(C f r$. Parte Primera, Cap. II) del trabajador (pto. I), de la ancianidad (pto. II), de la familia (pto. III), de la educación (pto. IV); derechos políticos (Cfr. Parte segunda, Sección Segunda, caps. I, II, III, IV) tales como los de elección directa del presidente (art. 82) y de reelección presidencial (art. 78), entre otros; y derechos humanos (Primera Parte, cap. II) como los de condena al delito de tormento (art. 29, §1), de hábeas corpus (art. 29, §2) y de protección contra la discriminación racial (art. 28).

Este nuevo orden regulatorio operaba especialmente proponiendo una nueva semántica sobre la propiedad privada, sujetándola a fines de bien común ( $C f r$. Primera Parte, cap. IV, art.38) 
Massariol, D.N. Horizonte iusnaturalista de impronta cristiano-humanista en la «justicia social» del programa estético oficial peronista (1946-1955) . Derecho y Ciencias Sociales. Noviembre 2020 - Abril 2021. № 24 .Pgs 79 -99 ISSN 1852-2971. Instituto de Cultura Jurídica y Maestría en Sociología Jurídica. Facultad de Ciencias Jurídicas y Sociales. Universidad Nacional de La Plata. Argentina.

y del bienestar social nacional (Cfr. Primera Parte, cap. IV, art.39). Esta nueva condición, heredera de las fuentes cristianas (particularmente tomistas) que circulaban en la dogmática de los juristas nacionalistas contemporáneos (Koening 2015), se proponía discutir especialmente con la exclusión económica hacia una nueva política de mayorías. Es decir, si bien no se abrogaba la potestad individual sobre la propiedad, ${ }^{9}$ se disponía con ello su servicio al interés colectivo. Desde allí se sostendrá un universo judicial destinado, en definitiva, a conciliar el derecho y la realidad social, reorganizando el diálogo individuo-comunidad y adecuando los derechos de la libertad e igualdad a un marco de despliegue y concreción de la «justicia social». En consecuencia, el Estado pasaba de ser el protector de los bienes civiles privados a ser el garante de los intereses populares.

Por todo ello, la juridificación de los aspectos sociales producida en el período, al interior de la renovación mundial occidental del derecho social, además de funcionar como un instrumento legal necesario para la transformación buscada, se trataba sobre todo de un programa complejo de legalización política de la «justicia social». Es decir, el orden legal instaurado (y su concreción sistémica con la Constitución Nacional de 1949) tenía por fin último la institucionalización jurídica de un proyecto de nación (Cholvis 2015). ${ }^{10}$ Por ello, la ortodoxia y el ordenamiento del canon de «justicia» que impulsaba su promulgación, antes que la concreción de un nuevo escenario normativo, más bien significó la habilitación legal de un programa socio-cultural más amplio, subsidiario de la expansión política.

\section{Discusión final y conclusiones provisionales}

Desde este análisis iusfilosófico de la «justicia social» estilizada sobre un corpus de textos visuales vinculados al programa estético oficial justicialista, se ha podido fundamentar que su naturaleza jurídica se apoyó en un contenido suprapositivo católico de expresión cristianohumanista pero progresivamente secularizado hacia las bases de un nacionalismo. Estos hallazgos pudieron ser contrastados con la reconstrucción del proceso de transformación ideológica sucedido en el ámbito de los catolicísimos argentinos de 1930 por el cual, a finales de la década, terminó circulando un mayor interés por las interpretaciones del contexto social

\footnotetext{
${ }^{9}$ La propiedad privada de los bienes exteriores y el derecho de usar y disponer de ella, así como la prohibición de leyes confiscatorias y la exigencia de la indemnización para todos los casos de expropiaciones, quedan garantizados conforme al art. 14 de la nueva Constitución (v. Sampay 1949).

${ }^{10}$ De allí también que la Constitución Nacional no se trate solo de un compendio normativo para la regulación de los bienes jurídicos ya existentes sino, por sobre todo, de una declaración programática de los principios y aspiraciones de regular los bienes jurídicos que deben existir; i.e.: «fija los medios preferidos por un Estado concreto para alcanzar sus fines» (Sampay 1961).
} 
Massariol, D.N. Horizonte iusnaturalista de impronta cristiano-humanista en la «justicia social» del programa estético oficial peronista (1946-1955) . Derecho y Ciencias Sociales. Noviembre 2020 - Abril 2021. № 24 .Pgs 79 -99 ISSN 1852-2971. Instituto de Cultura Jurídica y Maestría en Sociología Jurídica. Facultad de Ciencias Jurídicas y Sociales. Universidad Nacional de La Plata. Argentina.

y ampliándose la discusión sobre su resolución en un futuro próximo; proceso que receptará coherente y sistemáticamente el Justicialismo en el derrotero de la década siguiente y que tomará como base ideológica para sus prácticas políticas. Asimismo, también se ha podido evidenciar la continuidad de este corpus de ideas en el programa legal justicialista y su conformidad con la renovación mundial occidental contemporánea del Derecho en el constitucionalismo social, a los fines de institucionalizar un nuevo orden jurídico nacionalpopular que sirviera de sustento legal para la transformación social buscada. Por ello, atentos a la lectura integral de las fuentes visuales y verbales relevadas en este estudio e inscriptos al interior de la discusión abierta por la bibliografía metatextual sobre el período, los hallazgos aquí planteados confluyen en la denominación de un nacionalismo social cristiano progresivamente secularizado como categoría analítica del proyecto político-socio-cultural justicialista.

A partir de este punto en la discusión se abren dos posibles formulaciones conclusivas. En principio, (1) que todas las transformaciones sociales de los primeros gobiernos de Perón se inscribieron siempre dentro de un marco legal de calidad y claridad jurídica, cuyo objetivo final era la creación de una nueva institucionalidad hacia la consolidación de un Estado fuerte (Palacio, 2018). Esto no implica que su proyecto político estuviera necesariamente separado por completo de las ideologías totalitarias del siglo XX ni que progresivamente su programa haya derivado en un autoritarismo; pero sí concuerda con el carácter fuertemente institucionalizador de su aparato de intervención y regulación social, el cual estuvo siempre habilitado por un programa legislativo, producido e implementado ad hoc. En segundo lugar, por evidenciar su inscripción en la tradición, (2) que el modelo explicativo justicialista puede definirse bajo un claro sentido pluritópico, creolizante y traslativo. En este sentido, los diferentes códigos y memorias residuales apropiados y reorganizados en su programa estético hacia la conformación de múltiples y nuevas combinaciones advierte, por sobre todo, la condición pragmática de su propio sistema modelizante. Esto, en definitiva, se relaciona con que el significado de todo signo se encuentra en constante definición y redefinición según la experiencia específica de su lectura (Mancuso, 2010).

Finalmente, este trabajo ha permitido reflexionar sobre la condición siempre histórica y social del Derecho, advirtiendo que el ordenamiento legal de una sociedad siempre expresa la ideología jurídica dominante de su contexto específico de configuración. Este enfoque crítico hacia las teorías, heurísticas, doctrinas y criterios jurisprudenciales circulantes en una época tiende a desidealizar cualquier tipo de convencionalismo jurídico hegemónico y a discutir su 
Massariol, D.N. Horizonte iusnaturalista de impronta cristiano-humanista en la «justicia social» del programa estético oficial peronista (1946-1955) . Derecho y Ciencias Sociales. Noviembre 2020 - Abril 2021. No 24 .Pgs 79 -99 ISSN 1852-2971. Instituto de Cultura Jurídica y Maestría en Sociología Jurídica. Facultad de Ciencias Jurídicas y Sociales. Universidad Nacional de La Plata. Argentina.

derrotero de caras al futuro. De allí que una transformación de la ortodoxia, tal la propuesta por el Justicialismo durante sus años de gobierno, haya debido de surgir de la reinterpretación previa de los conflictos reales, a la luz de la vivencia social fáctica. Solo así el Derecho argentino pudo lograr un mayor acercamiento a la cultura y, por ello, habilitar a la sociedad política a actuar legítimamente en consecuencia.

\section{Bibliografía de referencia}

Abásolo, E. (2002). «La dimensión política de la Corte Suprema durante el régimen peronista (1947-1955)» en EIAL [en línea], XIII, 2.

Barbero, M. I. y Devoto, F. (1983). Los nacionalistas (1910-1932). Junín: Centro Editor de América Latina.

Baschetti, R. (2015). La incesante publicística. Folletos del primer peronismo (1945-1955). Buenos Aires: Biblioteca Nacional.

Bergalli, R. (1984). Estado democrático y cuestión judicial. Buenos Aires:Ediciones Desalma.

Bianchi, S. (1989). «El ejemplo peronista. Valores morales y proyecto social (1951-1954)» en Anuario de Estudios Histórico y Sociales, 4. Tandil: IEHS; UNCPBA.

Bianchi, S. (2001). Catolicismo y peronismo. Religión y política en la Argentina 1943-1955, Tandil: IEHS.+

Blanco, J. (2008). «Componentes identitarios del imaginario de la Juventud Obrera Católica» en Cuadernos de Historia. Serie economía y Sociedad, Área de Historia del CIFFyHUNC, 10, pp. 83-118.

Bosca, R. (1997). La Iglesia Nacional Peronista. Factor religioso y poder político, Buenos Aires: Sudamericana.

Buchrucker, C. (1987). Nacionalismo y peronismo. La Argentina en la crisis ideológica mundial, Buenos Aires: Sudamericana.

Caimari, L. (1994). Perón y la iglesia católica. Religión, Estado y sociedad en la Argentina (1943-1955) Buenos Aires: Ariel; Buenos Aires: Planeta.

Caimari, L.. (2004). Apenas un delincuente. Crimen, castigo y cultura en la Argentina (1880 - 1955). Buenos Aires: Siglo XXI.

Campione, D. (2007). Orígenes estatales del peronismo. Buenos Aires: Miño y Dávila.

Cholvis, J. F. et al. (2015). La Constitución de 1949. Vigencia de sus principios básicos y consecuencias de su derogación. Buenos Aires: Honorable Cámara de Diputados de la Nación. 
Massariol, D.N. Horizonte iusnaturalista de impronta cristiano-humanista en la «justicia social» del programa estético oficial peronista (1946-1955) . Derecho y Ciencias Sociales. Noviembre 2020 - Abril 2021. No 24 .Pgs 79 -99 ISSN 1852-2971. Instituto de Cultura Jurídica y Maestría en Sociología Jurídica. Facultad de Ciencias Jurídicas y Sociales. Universidad Nacional de La Plata. Argentina.

Cordero Quinzacara, E. (2008). «De la propiedad a las propiedades. La evolución de la concepción liberal de la propiedad» en Revista de Derecho de la Pontificia Universidad Católica de Valparaiso [en línea], XXXI,493-525, 2do Semestre, 2008.

Devoto, F. (2002). Nacionalismo, fascismo y tradicionalismo en la Argentina moderna. Una historia, Buenos Aires: Siglo XXI.

Echeverría, O. (2014). «Virtudes de la doctrina y errores de la política. Monseñor Gustavo Franceschi ante los "totalitarismos" soviético, fascista y nacionalsocialista» en Quinto Sol, 21, I, enero-abril 2017, pp. 1-24.

Eco, U. (1975). Tratado de semiótica general, Barcelona: Lumen, 2000.

Eco, U. (1979a). Lector in fabula, Barcelona: Lumen, 1999.

Eco, U. (1979b). «Perspectivas de una semiótica de las artes visuales», en Criterios [en línea], La Habana, 2007, 25-28:221-233.

Eco, U. (1984). Semiótica y filosofía del lenguaje, Barcelona: Lumen.

Ewald, F. (1997). «El concepto de derecho social» en Contextos. Revista Crítica de Derecho Social,1, 101-ss.

Ghio, J. M. (2007). La iglesia católica en la política argentina, Buenos Aires: Prometeo Libros.

Horwitz, M. J. (1992). The Transformation of American Law 1870-1960.The Crisis of Legal Orthodoxy. Oxford: Oxford University Press PALACIO, Juan M.

Horwitz, M. J. (2008). «El primer peronismo en la historiografía reciente: nuevas perspectivas de análisis» en Iberoamericana [en línea] X, 39, 255-265.

Horwitz, M. J. (2018). La justicia peronista. La construcción de un nuevo orden legal en Argentina. Buenos Aires: Siglo XXI.

Jauretche, A. (1973). FORJA y la década infame. Buenos Aires: Peña Lillo.

Kirchheimer, O. (2001). Justicia política. Empleo del procedimiento legal para fines políticos. Madrid: Comares.

Koening, M. (2015). «Sampay, la Constitución de 1949 y la concepción peronista de la propiedad» en Cholvis J.F. (comp.), La Constitución de 1949. Vigencia de sus principios básicos y consecuencias de su derogación. Buenos Aires: Honorable Cámara de Diputados de la Nación.

Lida, M. (2005). «Catolicismo y peronismo: debates, problemas, preguntas", Boletín del Instituto de Historia Argentina y Americana Emilio Ravignani, $\mathrm{n}^{\mathrm{o}} 27$, 1er semestre.

Liwski, N. I. (2015). «Los derechos sociales, el sentido de la Constitución del año 1949» en Cholvis J.F. (comp.), La Constitución de 1949. Vigencia de sus principios básicos y 
Massariol, D.N. Horizonte iusnaturalista de impronta cristiano-humanista en la «justicia social» del programa estético oficial peronista (1946-1955) . Derecho y Ciencias Sociales. Noviembre 2020 - Abril 2021. No 24 .Pgs 79 -99 ISSN 1852-2971. Instituto de Cultura Jurídica y Maestría en Sociología Jurídica. Facultad de Ciencias Jurídicas y Sociales. Universidad Nacional de La Plata. Argentina.

consecuencias de su derogación. Buenos Aires: Honorable Cámara de Diputados de la Nación.

Mallimaci, F. (1988). El catolicismo integral en la Argentina (1930-1946), Buenos Aires: Biblos.

Mallimaci, F. (2011). Nacionalistas y nacionalismos. Debates y escenarios en América Latina y Europa, Buenos Aires: Gorla.

Mancuso, H. R. (2005). La palabra viva. Teoría textual y discursiva de Michail M. Bachtin, Buenos Aires: Paidós.

Mallimaci, F. (2010). De lo decible. Entre semiótica y filosofía: Peirce, Gramsci, Wittgenstein. Buenos Aires: SB.

Mancuso, H. R. \& Niño Amieva, A. L. (2011). «Ensayo de una semiótica visual en dibujos políticos de la Argentina de mediados del siglo XX» (en línea) en AdVersuS, diciembre, VIII, 21: 63-84. [Consultado 20-05-2018]

Mallimaci, F. (2016). «Lineamientos de una metodología semiótica de análisis visual» (en línea) en AdVersus, XIII, 31, pp. 48-86. [Consultado 20-05-2019].

Massariol, D. N. (2018). «Traducción intrasemiótica entre la enunciación visual del peronismo y la Segunda República para la construcción de un "lector modelo" (19461951)» en AdVersus [en línea], XV, 34, junio 2018, 70-104.

Mercilese, J. (2010). «La intervención del sistema judicial bonaerense durante el primer peronismo: la subordinación de la justicia al poder político» en Historia Constitucional, $11,275-296$.

Palacio, J. M. (2018). La justicia peronista. La construcción de un nuevo orden legal en Argentina. Buenos Aires: Siglo XXI.

Pestanha, F. J. (2015). «La Constitución de 1949 como producto histórico-cultural» en Cholvis, J.F. (comp.), La Constitución de 1949. Vigencia de sus principios básicos y consecuencias de su derogación. Buenos Aires: Honorable Cámara de Diputados de la Nación.

Santiago, A. (2001). «Historia de la Corte Suprema Argentina. Algunos lineamientos básicos y fuentes para su estudio» en A.A.V.V. El Derecho X. Buenos Aires: Universidad Católica Argentina, pp. 966-996.

Soler, S. (1966). Bases ideológicas de la reforma penal. Buenos Aires: Eudeba.

Tanzi, H. J. (1995). «La dimensión ideológica de la Corte Suprema de Justicia de la Nación 1947-1955» en IUSHISTORIA Revista Electrónica [en línea], 2, 1-74.

Zanatta, L. (1996). Del Estado liberal a la nación católica. Iglesia y Ejército en los orígenes del peronismo. 1930-1943. Quilmes: Universidad Nacional de Quilmes. 
Massariol, D.N. Horizonte iusnaturalista de impronta cristiano-humanista en la «justicia social» del programa estético oficial peronista (1946-1955) . Derecho y Ciencias Sociales. Noviembre 2020 - Abril 2021. № 24 .Pgs 79 -99 ISSN 1852-2971. Instituto de Cultura Jurídica y Maestría en Sociología Jurídica. Facultad de Ciencias Jurídicas y Sociales. Universidad Nacional de La Plata. Argentina.

Zanatta, L.. (1999). Perón y el mito de la nación católica. Iglesia y Ejército en los orígenes del peronismo 1943-1946, Buenos Aires: Sudamericana.

Zanca, J. A. (2006). Los intelectuales católicos y el fin de la cristiandad 1955-1966, Buenos Aires: Fondo de Cultura Económica.

Zanca, J. A. (2013). Cristianos antifascistas, Buenos Aires: Siglo XXI.

Zimmermann, E. (1995). Los liberales reformistas. La cuestión social en la Argentina. Buenos Aires: Sudamericana.

Zimmermann, E. (2012). Las prácticas del Estado. Buenos Aires: Edhasa.

Zuleta Alvarez, E. (1975). El Nacionalismo Argentino, Buenos Aires: La Bastilla

\section{Fuentes escritas}

Maritain, J. (1936a). Humanismo integral. Problemas temporales y espirituales de una nueva cristiandad. Madrid: Palabra, 1999.

Maritain, J. (1936b). Para una filosofía de la persona humana. Santiago de Chile: Letras, 1960.

Maritain, J.. (1948). Razón y razones. Buenos Aires: Desclée de Brouwer.

Sampay, A. E. (1949). Informe del convencional constituyente Arturo Sampay para la reforma constitucional de 1949. Buenos Aires: Archivo Histórico, Ministerio de Educación de la Nación.

\section{Fuentes visuales}

Escuela Superior Peronista. (1953-1954). Mundo Peronista. Buenos Aires: Haynes.

Presidencia de la Nación Argentina. (1948). 4 de Junio. Alfonsín (dis.). Buenos Aires: SIPA.

Presidencia de la Nación Argentina. (1949). El trabajador en la función pública. (S/f.) Buenos Aires: SIPA.

Presidencia de la Nación Argentina. (1950). La nación argentina justa, libre y soberana. Buenos Aires: Peuser.

Presidencia de la Nación Argentina. (1951). Argentina en marcha. Buenos Aires: Exlibris 